\title{
Gerçek Zamanlı Yüz Tanıma Tabanlı Personel Kontrol ve Takip Sistemi Tasarımı
}

\author{
Uğur Mamak ${ }^{1}$, Mehmet Zeki Konyar²*, Serdar Solak${ }^{3}$, Mustafa Hikmet Bilgehan Uçar ${ }^{4}$ \\ ${ }^{1}$ Kocaeli Üniversitesi, Teknoloji Fakültesi, Bilişim Sistemleri Müh. Bölümü, Kocaeli, Türkiye (ORCID: 0000-0002-3488-0566) \\ ${ }^{2}$ Kocaeli Üniversitesi, Teknoloji Fakültesi, Bilişim Sistemleri Müh. Bölümü, Kocaeli, Türkiye (ORCID: 0000-0001-8914-5553) \\ ${ }^{3}$ Kocaeli Üniversitesi, Teknoloji Fakültesi, Bilişim Sistemleri Müh. Bölümü, Kocaeli, Türkiye (ORCID: 0000-0003-1081-1598) \\ ${ }^{4}$ Kocaeli Üniversitesi, Teknoloji Fakültesi, Bilişim Sistemleri Müh. Bölümü, Kocaeli, Türkiye (ORCID: 0000-0002-9023-0023)
}

(İlk Geliş Tarihi 27 Nisan 2020 ve Kabul Tarihi 16 Haziran 2020)

(DOI: 10.31590 /ejosat.727768)

\begin{abstract}
ATIF/REFERENCE: Mamak, U., Konyar, M. Z., Solak, S. \& Uçar, H. B. (2020). Gerçek Zamanlı Yüz Tanıma Tabanlı Personel
\end{abstract} Kontrol ve Takip Sistemi Tasarımı. Avrupa Bilim ve Teknoloji Dergisi, (19), 497-504.

\section{$\ddot{O} z$}

Son yıllarda görüntü işleme ve bilgisayarlı görme çalışmaları hızla yayılmaya başlamıştır. Tarım, tıp, eğitim, sağlık ve güvenlik gibi birçok alanda bilgisayarlı görme çalışmaları yapılmakta ve günlük yaşantımızda kullanılmaktadır. Özellikle yüz ve nesne tanıma işlemi, her geçen gün farklı birçok uygulama ile karşımıza çıkmaktadır. Geliştirilen bu yüz tanıma uygulamaları ile kullanıcılardan yüz bilgileri toplanarak veri ve bilgi tabanları oluşturulmaktadır. Okul, işyeri, site, alışveriş merkezi, stadyum gibi birçok sosyal alanların kontrol ve takip edilmesinde bu uygulamalar ve veritabanları kolaylık sağlamaktadır. Makale kapsamında, işyerlerinin personel giriş ve çıkışlarını hızlı, etkili ve doğru bir şekilde takip etmesi amacıyla, yüz tanıma tabanlı personel kontrol ve takip sistemi tasarımı önerilmektedir. Çeşitli işyerlerinde personel giriş çıkışlarının kontrol edilmesi genellikle kartlı sistem veya el ile kayıt tutularak yapılmaktadır. Bu tarz sistemlerde başkasının yerine kart basma veya eksik isim yazma gibi insan kaynaklı problemler ortaya çıkmaktadır. Ayrıca personel sayısının fazla olduğu firmalarda personel giriş çıkışlarının takip edilmesinde ciddi problemler yaşanmaktadır. Özellikle yakın zamanda ortaya çıkan salgın hastalıklardan sonra herkesin aynı yere kart basması veya parmak izi okutması hijyen ve sağlık koşulları açısından oldukça sıkıntılı bir durum olduğu ortaya çıkmıştır. Geliştirilen sistemde, giriş ve çıkışlara kameralar yerleştirilerek personellerin görüntüleri alınmaktadır. Alınan görüntülerden yüz bölgeleri tespit edildikten sonra, özyüz, fisheryüz ve yerel ikili örüntü histogramı yöntemleriyle yüzün kime ait olduğu bulunmaktadır. Bulunan kişiye ait giriş veya çıkış bilgisi ekranlarda gösterilmekte ve bu bilgi personel veritabanında saklanmaktadır. Yüz tanıma sistemi sayesinde personellerin işe geliş, gidiş saatleri ve fazla mesai bilgileri otomatik olarak kolayca takip edilmektedir.

Anahtar Kelimeler: Bilgisayarlı görme, Fisheryüz, Özyüz algoritması, Yerel ikili örüntü histogramı, Yüz tanıma.

\section{Real Time Face Recognition Based Personnel Control and Tracking System Design}

\begin{abstract}
Image processing and computer vision have started to spread rapidly in recent years. Computer vision studies are carried out in many fields such as agriculture, medicine, education, health and security and are used in our daily life. Especially face and object recognition process comes up with many different applications day by day. Thanks to these face recognition applications developed, databases are
\end{abstract}

*Sorumlu Yazar: Kocaeli Üniversitesi, Teknoloji Fakültesi, Bilişim Sistemleri Müh. Bölümü, Kocaeli, Türkiye, ORCID: 0000-0001-8914-5553, mzeki.konyar@kocaeli.edu.tr 
created by collecting facial information from users. These applications and databases will facilitate the control and monitoring of many social areas such as schools, workplaces, sites, shopping centers, stadiums. In this article, it is proposed to design a face recognition based personnel control and tracking system in order to track the personnel entrances and exits quickly, effectively and accurately. Controlling the entrances and exits of employees in various workplaces is generally done by card system or by keeping a manual record. In such systems, human-related problems such as printing cards or typing incomplete names occur instead of someone else. In addition, there are serious problems in tracking the number of personnel entrances and exits in companies. Especially after recent epidemic diseases, it has turned out to be a very troublesome situation in terms of hygiene and health conditions for everyone to scan cards or to have fingerprints in the same place. In this study, face recognition based personnel control and tracking system design was developed. In the developed system, cameras are placed on the entrance and exit and the images of the personnel are taken. After determining the facial regions from the images taken, it is determined to whom the face belongs by using eigenface, fisherface and local binary pattern histogram methods. The entry or exit information of the person found is displayed on the screen and this information is stored in the personnel database. Thanks to the face recognition system, personnel entry-exit times and overtime information are easily tracked automatically.

Keywords: Computer vision, Eigenface, Face recognition, Fisherface, Local binary pattern histogram.

\section{Giriş}

Yüz tanıma yöntemleri, ticari kullanım ihtiyacının yanı sıra, artan güvenlik ihtiyaçlarını gidermek için de geliştirilmektedir. Uygulanan yüz tanıma yönteminin, düşük hataya sahip olması, farklı pozlardaki çekimlerde bile yüksek başarı ile yüzü tanıması ve diğer biyometrik yöntemlerden daha hızlı çalışması onu öne çıkarmaktadır. Yüz tanımanın en önemli avantajlarından biri de klasik kimlik tespit yöntemlerine göre daha yüksek güvenlik sağlamasıdır. Yüz tanıma işlemi iki kısımda gerçekleşmektedir. İlk olarak görüntüdeki yüzün algılanma aşamasıdır. $\mathrm{Bu}$ aşamada şablon eşleştirme, bilgi tabanlı yöntemler gibi metotlar kullanılarak yüz algılanmaktadır. Tespit edilen yüzlerin tanınabilmesi için veritabanında kişiye ait birden fazla poz ve varyasyonda çekilmiş yüz görüntüleri bulunmalıdır.

Yüz algılama, yüz tanıma için ilk ve temel adımdır ve görüntülerdeki yüzleri algılamak için kullanılır. Yüz tespiti ve tespit edilen yüzün konumlandırılması işlemi yüz tanıma uygulamalarında kullanılan en önemli ön işlemlerden birisidir. Yüz tespitini zorlaştıran etmenlere bakıldığında, yaş, yüzün bir kısmının kapanması, poz değişimi, yüzün aydınlanması, karmaşık arka plan, ten rengi ve mesafe öne çıkmaktadır (Lal vd., 2018; Kumar vd., 2019). Yüz tanıma yöntemleri öznitelik tabanlı ve şablon resimlere dayalı yöntemler olarak ikiye ayrılabilir. Resim şablonuna dayalı yöntemler, veritabanlarında tutulan resimlerle karşılaştırma yaparak tespit işlemini gerçekleştirir. Öznitelik tabanlı yöntemler ise gözler, kaşlar, ağız, burun saç hattı gibi yapısal özelliklerin yerleri değişmemesini esas alır. Bu yapısal özellikler arasındaki ilişkiler için istatistiksel modeller çıkartılarak yüz tespiti sağlanır (Kumar vd., 2019).

Yüz tanıma uzun zamandır kullanılmasına rağmen günlük hayatta yaygınlaşması yakın zamanlarda olmuştur. Özellikle akıllı telefonların ve tabletlerin yaygınlaşması yüz tanımayı daha da popüler hale getirmiştir. Cinsiyet tespiti, evrak kontrolü, otomatik fotoğraf çekimi, duygu tanıma gibi alanlarda sıklıkla kullanılırken biyometrik tanıma ve takip için de başvurulan bir yöntem olmaya başlamıştır. Selvi vd., (2014) çalışmasında bir üniversitedeki öğrencilerin yoklamasını otomatik almak için bir yöntem önermişlerdir. Oldukça basit ve temel düzeydeki bu yöntemde temel bileşen analizi tabanlı yüz tanıma yapılmıştır. Holat \& Kulaç, (2014) çalışması ise hazır bir veritabanı üzerinden yüz tanıma uygulaması yapmıştır. Bu çalışma, yüz tanıma yöntemlerini, histogram eşitleme ve filtreleme işlemlerinin kullanımına göre karşılaştırmıştır. Ayrıca farklı pozlardaki yüzlerin tespit edilme durumlarını incelemiştir. Turan, (2017) çalışmasında yüz tanımayla öğrenci yoklaması yapılırken, öğrencilerin ders süresince duygusal değişimlerini de takip etmek için bir çalışma yapılmıştır. Taşınabilir sistemlerle öğrenci yoklaması yapan yöntemlerden Patel vd., (2018) çalışmasının yazarları raspberry pi kullanarak, Bhattacharya vd., (2018) çalışmasının yazarları da basit bir gömülü sistem kullanarak yüz tanıma tabanlı takip sistemi geliştirmişlerdir. Öğrenci yoklama takibi yapan diğer bir yöntemde ise (Nandhini vd., 2019) derin öğrenme yaklaşımlarıyla sınıftaki mevcut öğrenciler tespit edilmektedir. Avuçlu vd., (2017) çalışmasında Temel bileşen analiz yöntemiyle yüz tanıma yapılarak, işe geç gelen veya işten erken çıkan kişilerin tespit edilmesi amaçlanmıştır. Kadlag vd., (2018) çalışmasında yüz tanıma, kartlı geçiş sisteminin kontrolü için kullanılmaktadır. Kartı basan kişinin resmi çekilip, kart sahibinin sistemdeki yüzü ile karşılaştırılmaktadır. Kartı basan kişi, kartın sahibi ise geçişine izin verilmektedir.

\section{1. Çalışmanın Avantajları}

Kartlı takip sistemlerinde, kart basma işlemi hem zahmetli hem de zaman kaybına sebep olmaktadır. Kartlı takip sistemlerinde yanlış beyan yani kartın başkası tarafından okutulması da diğer bir problemdir. Parmak izi ve diğer biyometrik takip sistemleri de güvenli yöntemler olmakla beraber zaman kaybını önleyememektedir. Bunun yanında özellikle yakın zamanda ortaya çıkan salgın hastalıklardan sonra herkesin aynı yere kart basması, parmak izi veya iris okutmasının hijyen ve sağlık koşulları açısından oldukça sıkıntılı bir durum olduğu ortaya çıkmıştır. Bunun için bu çalışmada önerilen yüz tanıma tabanlı takip sistemi biyometrik özellikleri kullanması sebebiyle güvenilir bir yöntemdir. Personelin giriş ve çıkışlarda kameraya bakması dışında bir işlem gerektirmediği için hem hızlı hem de sağlık koşullarına uygun bir yöntemdir. Ayrıca, insan faktöründen kaynaklanan sorunların önüne geçerek, işletmelerde yüz tanıma sistemi ile personel giriş çıkış saatlerini dijital ortama kaydederek, fazla mesai bilgilerinin hesaplanmasına destek olurken, devam takibi için raporların elde edilmesini sağlamaktadır. Bu sayede insan faktöründen kaynaklanan hatalar en aza indirgenmektedir. Bunların yanı sıra elde edilen bu raporlar yöneticilere daha doğru bilgiler vererek anlık, günlük veya aylık durumları kolayca görmelerini sağlamaktadır. 


\section{Materyal ve Metot}

Yüz tanıma sistemi sayısal bir görüntüden veya bir video karesinden bir kişiyi tanımak ve doğrulamak amacıyla kullanılır. Yüz tanıma sistemlerinde kullanılan çok sayıda yöntem vardır. Bu sistemlerin genel yapısı belirli yüz görüntülerinden elde edilmiş özellikleri içeren dosyalar ile tanımlı yüzlerin karşılaştırılması mantığı vardır. Ayrıca, kişinin yüz dokularına ve şekline dayanan kalıpları analiz ederek bir kişiyi benzersiz şekilde tanımlayabilen biyometrik yapay zekâ tabanlı uygulamalar da geliştirilmektedir. Yüz tanıma sisteminin biyometrik bir teknoloji olarak doğruluğu, iris tanıma ve parmak izi tanıma seviyesinden düşük olsa da, temassız ve invazif olmayan işlemlerinden dolayı yaygın olarak kullanılmaktadır. Yakın zamanlarda, ticari pazarlama ve tanımlama aracı olarak da popüler hale gelmiştir. Bu kapsamda firmaların personellerini etkili ve doğru bir şekilde takip etmesi için yüz tanıma tabanlı personel kontrol ve takip sistemi önerilmektedir. Önerilen bu sistem sayesinde firmada yer alan personeller sisteme hızlı bir şekilde kaydedilmekte ve giriş-çıkışları kayıt altına alınmaktadır. Şekil 1'de bu çalışma kapsamında gerçekleştirilen yüz tanıma tabanlı kontrol ve takip sistemine ait blok şeması sunulmaktadır.

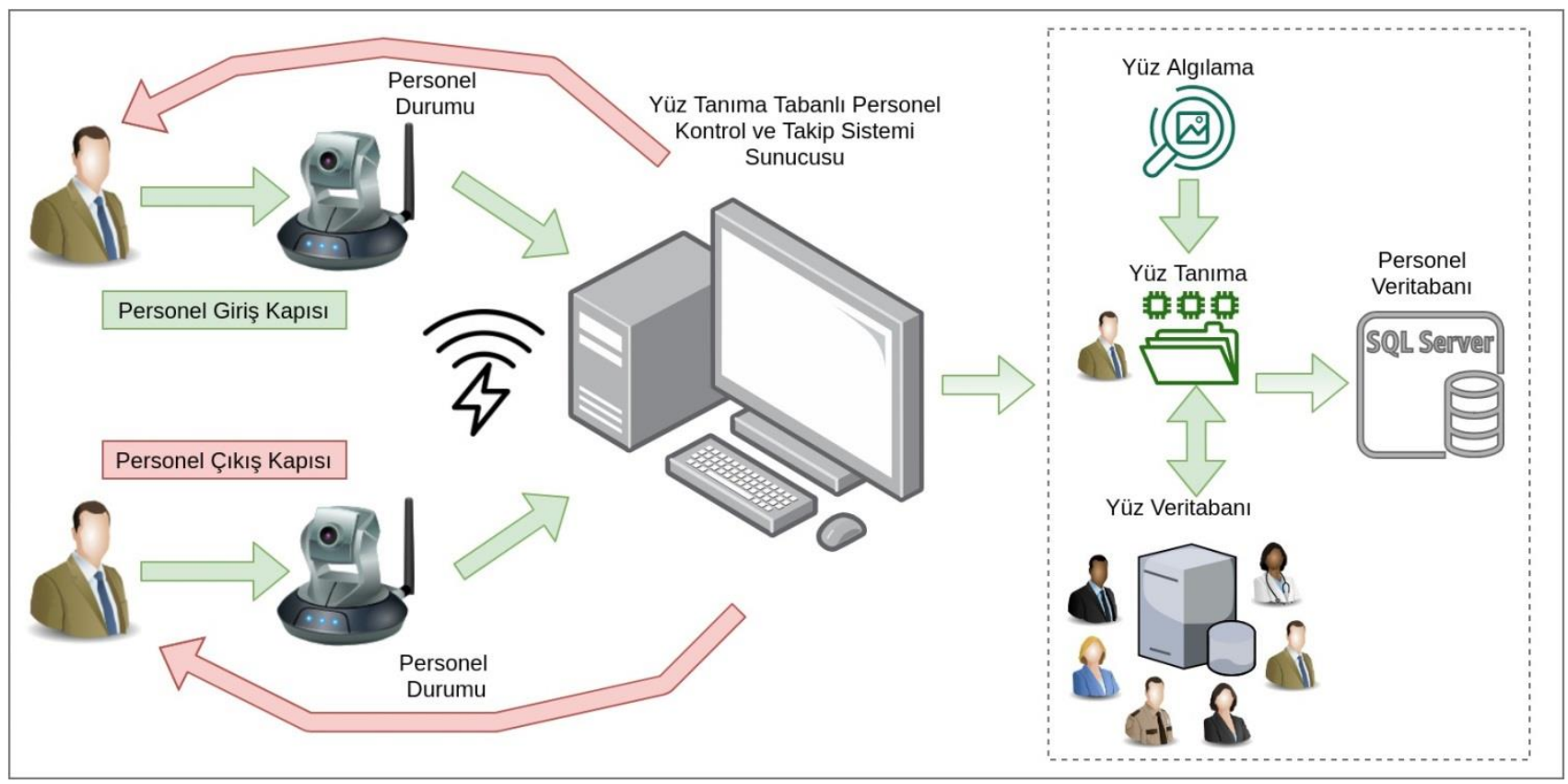

Şekil 1. Önerilen yüz tanıma tabanlı kontrol ve takip sistemi

Önerilen sistemde işyerinin giriş ve çıkışlarına personellerin yüz görüntülerini almak amacıyla kablolu veya kablosuz kameralar yerleştirilmektedir. Bu kameralar sayesinde alınan görüntüler sunucu bilgisayarda görüntü işleme teknikleri kullanılarak işlenmektedir. Alınan görüntülerde ilk olarak, yüz olup olmadığı tespit edilmektedir. Eğer sistem tarafından yüz tespit edildiyse, yüzün kime ait olduğu personel veritabanından kontrol edilmektedir. Giriş veya çıkışta yüzü algılanan kişi yüz veritabanında yer alıyorsa, personel veritabanına ilgili bilgileri yazılmaktadır. Eğer yüz veritabanında yer almayan bir kişi algılandıysa misafir veya yeni personel olarak tanımlanabilir. Gerçekleştirilen sistem ile yöneticiler personellerin durumlarını istedikleri zaman kontrol edebilirler. Önerilen çalışmada özyüz, fisheryüz ve yerel ikili örüntü histogramı (LBPH) olmak üzere üç farklı yöntem ile yüz tanıma işlemi yapılabilmektedir.

Yüz tanıma işleminin ilk adımı, görüntülerde yüz algılama işleminin başarılı ve doğru bir şekilde gerçekleştirilmesidir. Bu amaçla kullanılan yüz algılama yöntemleri, görüntülerin yüzlü (pozitif) görüntüler veya yüzsüz (negatif) görüntüler olup olmadığını belirlemeye çalışırlar (Hatem vd., 2015; Reddy, 2017). Yüz algılamanın en doğru biçimde yapılması için, algoritmaların yüzlü görüntüler ve yüz olmayan görüntüler içeren devasa veri kümeleri ile eğitilmeleri gerekmektedir. Yüz algılama algoritmaları "resimde herhangi bir yüz var mı", "varsa nerede" olduğunu sorularına cevap aramaktadırlar. Bu makalede yüz algılama işlemi için yaygın kullanılan Viola-Jones algoritmasından faydalanılmıştır. Algoritmanın ilk aşamasında, kayan pencere adı verilen yöntem kullanılarak kameradan alınan görüntü üzerinde soldan sağa ve yukarıdan aşağıya doğru tarama yapılmaktadır. Pencerenin içerisinde iki kaş, iki göz, burun ve ağızı temsil eden Haar benzeri özellikler aranmaktadır. Taramada kullanılan Haar benzeri özellikler Şekil 2'de gösterilmektedir. Örneğin görüntüde kaş arama işleminde kaşın koyu renkten oluşması üst tarafının ise açık renk olmasından dolayı kenar özellik varlığına bakılmaktadır. Benzer şekilde dudak, burun ve gözler için de ilgili özelliklere bakılmaktadır.

Taramada kullanılan pencere boyutları büyütülüp küçültülerek resim tekrar tekrar taranmakta ve kaçırılan yüzler varsa onlar da bulunmaya çalışılmaktadır. Algoritmada kullanılan Haar benzeri özelliklerinin çok hızlı bir şekilde hesaplama yapması için integral resmi kullanılmaktadır. Yüz tanıma algoritmasının hızlı çalışması için renkli görüntüler yerine gri görüntüler üzerinde aramalar yapılmaktadır.

Görüntüdeki yüz algılandıktan sonra, o yüzün kime ait olduğu tespit edilmeye çalışılır. Yüz tanıma olarak adlandırılan bu işlemin gerçekleştirilmesinde çok sayıda algoritma kullanılmaktadır. Bu makaledeki yüz tanıma işlemi için özyüz, fissheryüz ve yerel ikili örüntü histogramı yöntemleri kullanılmıştır. 


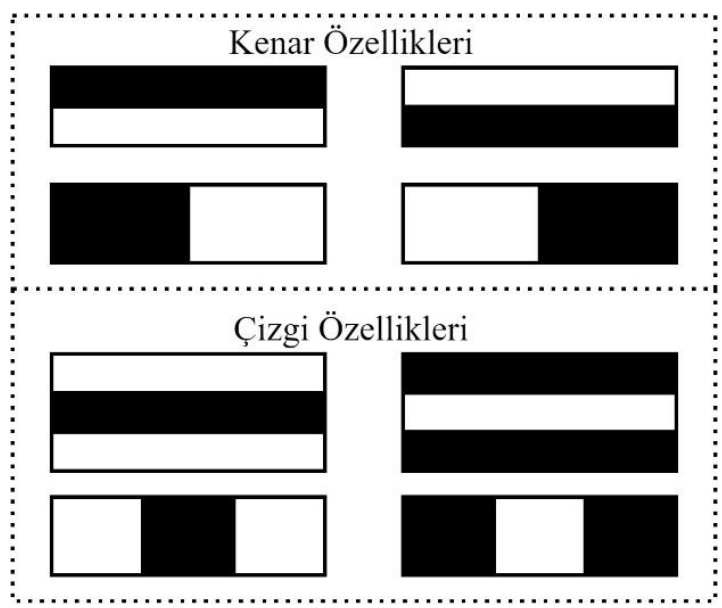

Şekil 2. Yüz algılama için kullanılan Haar benzeri özellikleri

Makale kapsamında ve yüz tanımada yaygın kullanılan öz yüzler (Eigenfaces) yöntemi, Temel Bileşenler Analizi adı verilen Principal Component Analysis (PCA) tekniği kullanmaktadır. Yöntem, yüz görüntülerinden elde edilecek yüz veritabanı içerisinde, yüz görüntüsünü temsil edecek en iyi vektörüne ait temel bileşenleri aramakta ve veri kümesini oluşturulmaktadır. Temel bileşenleri temsil eden bu vektör görünüm olarak yüze benzediğinden “özyüz” adını almıştır. Temel bileşenlerin ve vektörün elde edilmesinde, veri kümesi üzerinde çeşitli istatistiksel hesaplamalar kullanılarak boyut indirgemesi ve yorumlaması yapılmaktadır. Yöntemin temel yapısında, boyut indirgemesi gerçekleştirildiği için, veri seti küçülmekte ve yöntem gerek eğitim aşamasında gerek tanıma işleminde hızlı çalışmaktadır (Kekül vd., 2018)

Çalışmada kullanılan Fisheryüz algoritması özyüz algoritmasının geliştirilmesiyle ortaya çıkmıştır. Algoritma boyut indirgeme işleminde, Doğrusal Ayraç Analizi (DAA) yapısını kullanmaktadır. DDA yaklaşımı kullanılarak geliştirilen bu yüz tanıma algoritmasında, bir kişiye ait çok sayıda farklı yüz görüntüleri, yüz veritabanına eklenmekte ve sınıf içi dağılımı minimuma, sınıflar arası dağılımı ise maksimuma çıkarmayı hedeflemektedir. Bu sayede, benzer özelliklerin kümelenmesi sağlanmaktadır. Özellikle, gerçek zamanlı uygulamalarda, Fisheryüz algoritması, görüntü ön işleme adımlarının fazla olmasından dolayı yavaş sonuçlar veren bir yöntemdir (Erdoğan \& Ilgın, 2015; Kabasakal, 2018; Holat \& Kulaç, 2014).

Yüz tanıma çalışmalarında performans yüksekliğinden dolayı çalışmada kullanılan diğer algoritma ise yerel ikili örüntü histogramı yöntemidir. Hesaplama karmaşıklığının az olması ve sınıflandırmadaki başarılarından dolayı gerçek zamanlı yüz tanıma sistemlerinde yaygın kullanılmaktadır. Yöntemde temel yaklaşım olarak, yerel komşuluk ilişkilerine bakılmakta ve öznitelikler çıkarılmaktadır (Vurgun, 2017)

\section{Geliştirilen Personel Kontrol Sistemi}

Bu çalışmada geliştirilen personel kontrol sistemi için grafik arayüz tasarlanmıştır. Personellerin tüm giriş çıkış işlemleri yüz tanıma sistemiyle otomatik olarak, hızlı ve doğru bir şekilde takip edilmektedir. Bunun için ilgili giriş ve çıkş̧ kapılarına kameralar yerleştirilmiştir. Bu kameralar sayesinde personellere ait yüzler taratılmakta ve işlemek amaciyla sunucu bilgisayara gönderilmektedir. Bu bilgisayardan personel yüzleri algılandıktan sonra, yüzün kime ait olduğunu tespit için yüz veritabanından sorgulama yapılarak giriş çıkış işlemleri gerçekleştirilmektedir.

\subsection{Yüz Tanıma Sistemin Eğitilmesi ve Yeni Personel Ekleme}

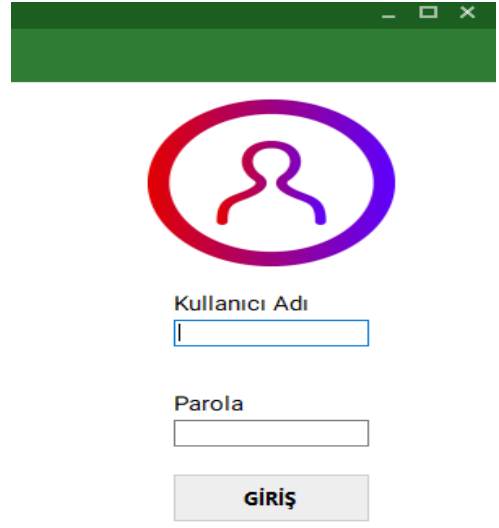

(a)
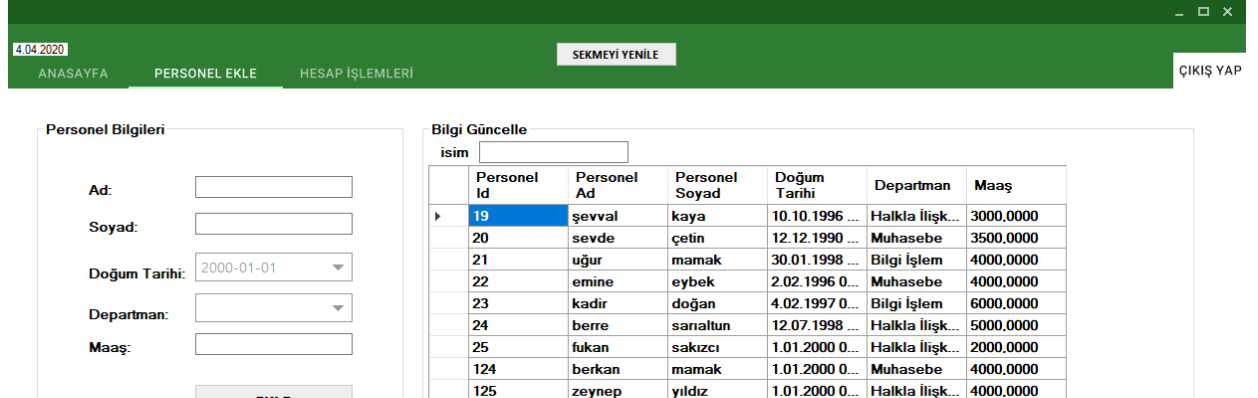

EKLE

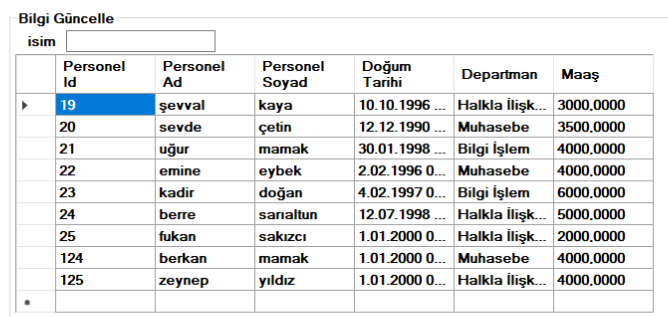

(b)

Şekil 3. Geliştirilen arayüz. (a) sisteme giriş (b) personel bilgisi ekleme

Geliştirilen yazılımda yüz tanıma sisteminin ilk defa eğitilmesi için "Labeled Faces in the Wild” (Huang vd., 2007) veritabanındaki yüzler kullanılmıştır. Otomatik olarak tanınması istenen her bir personel için kişisel bilgiler ve farklı pozlardaki yüz görüntüleri, yüz ve 
personel veritabanına kaydedilmektedir. Önerilen sistemde giriş çıkış ekranından elde edilen bilgilerin veritabanına kaydedilmesi için arayüzler tasarlanmıştır. $\mathrm{Bu}$ arayüzler personel kaydetme, güncelleme, filtreleme, doküman elde etme gibi işlemlerin gerçekleştirilebilmesine imkân sağlamaktadır. Geliştirilen sistemi kullanacak yetkili kişilerin kullanıcı adı ve parolayla erişebildiği giriş ekranı Şekil 3(a)'da gösterilmektedir. Sisteme giriş yapan yetkili kişi, yeni personele ait ilgili bilgileri Şekil 3(b)'de sunulan ekrandan girmektedir.

Bilgileri eklenen personelin yüzünün sisteme tanıtılması işlemi için eğitim verilenin eklendiği yüz paneli açılmaktadır. İlgili personelin resmi çekilir ve yüz algılama işlemi yapılır. Yüz algılandıysa ilgili resim veritabanına eklenir. Değişik pozlarla çekilen resimlerin her birisinden de yüz algılama işlemi yapılarak ilgili yüzler veritabanına eklenir. Hatalı tespit ihtimallerine karşı, yüz algılamanın olmadığı resimler silinir. Şekil 4’te yeni personel resimlerinin eklenmesi gösterilmektedir. Önerilen sistem dinamik yapıda olduğundan herhangi bir personel için farklı zamanlarda yüz bilgilerinde güncelleme yapılabilmektedir. Böylece yüz yapısında ameliyat, kaza veya başka fiziksel değişimler sonucu meydana gelebilecek farklılıklara karşı önlem alınmaktadır.

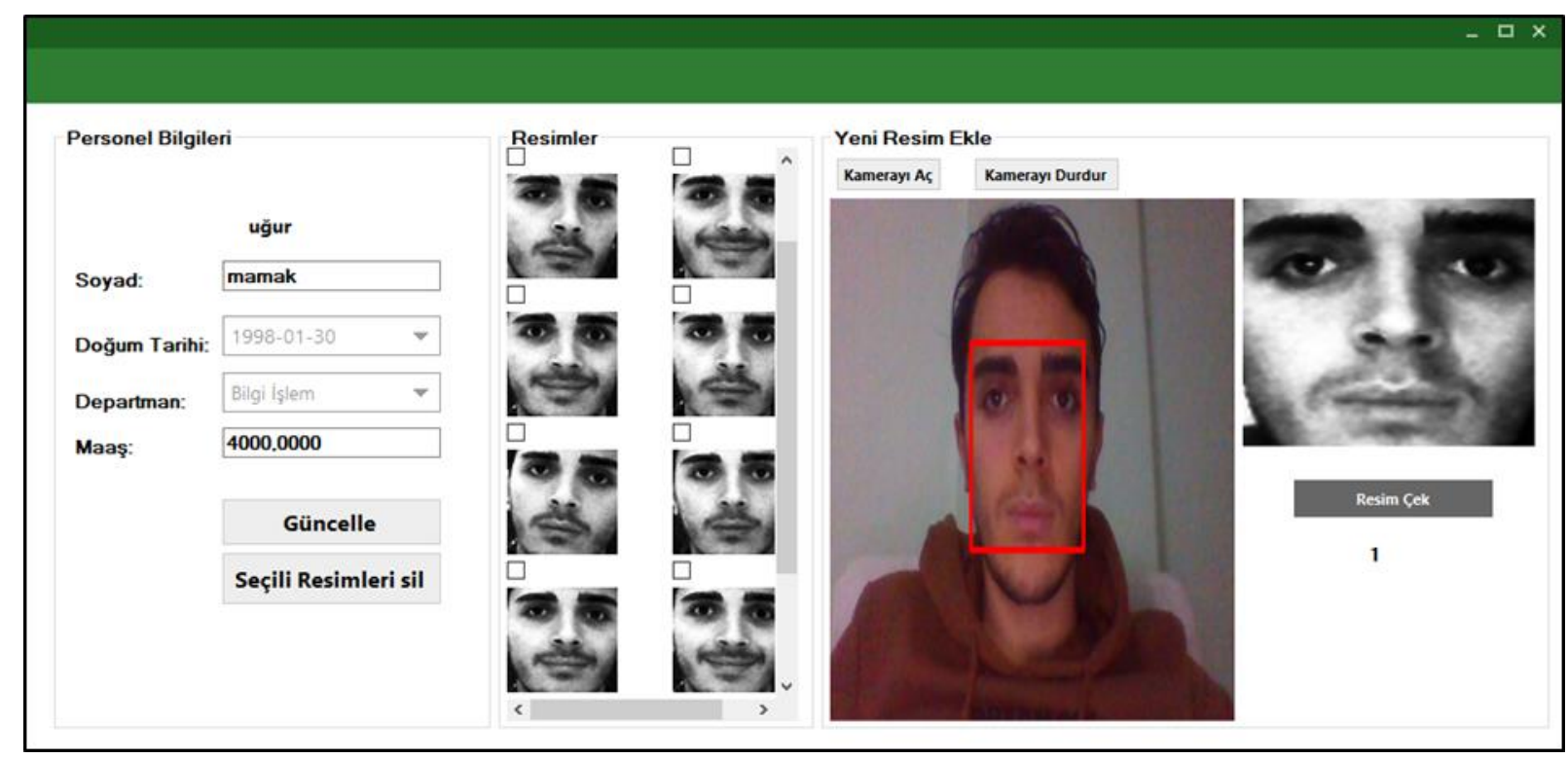

Şekil 4. Personel yüz ekleme ve güncelleme ekranı

Yüz görüntülerini sisteme eklerken bellekte daha az yer tutmaları gerekmektedir. Bunun yanı sıra görüntü ön işleme işlemlerinin hızlıca yapılması sistem performansı açısından önemlidir. Bu yüzden sisteme tanıtılan her bir yüz, çeşitli ön işlemlerden geçirilerek Şekil 5'teki gibi gri tonda kaydedilmektedir. Aksi durumda her bir personel için yüz tanıma süresi uzayacağı için özellikle mesai başlangıç ve bitiş saatlerinde gecikmelere ve uzun kuyruklar oluşmasına sebep olacaktır.
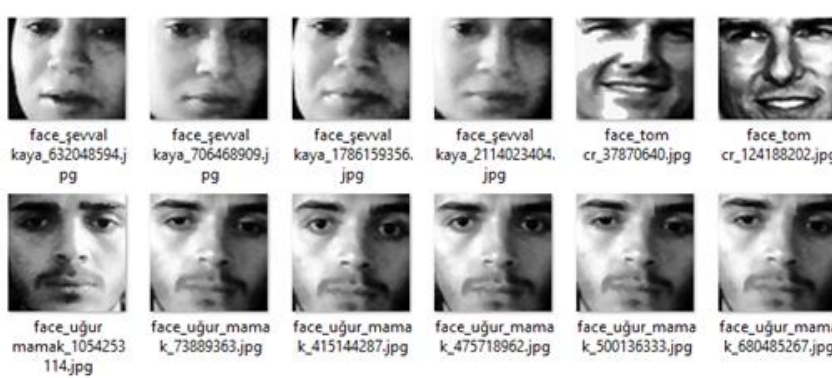

face_uğur_mama
k_475718962.jpg $\quad \begin{gathered}\text { face_uğur_mama } \\ k_{-} 500136333 . j p g\end{gathered}$
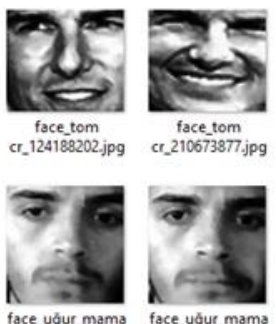

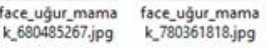

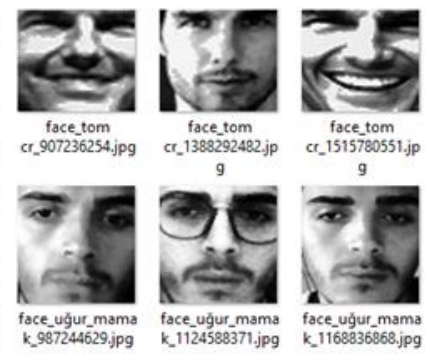

Şekil 5. Sisteme eklenen gri yüz görüntüleri

\subsection{Giriş-Çıkışlarda Yüz Tanıma}

Önerilen sistemde yüz tanıma işlemi giriş çıkışlarda bulunan kameralar kullanılarak yapılabilmektedir. Kameralara dışarıdan müdahale edilmediği sürece, geliştirilen sistem tüm giriş çıkışlarda yüz tanıma işlemini ve giriş çıkış bilgisini kayıt altına almaktadır. Bunun için her bir personel giriş veya çıkış esnasında kameraya yüzlerini taratmak zorundadır. Kameradan gelen görüntüde ilk olarak yüz algılama işlemi gerçekleştirilir. Ön işlemler yapıldıktan sonra elde edilen görüntü yüz tanıma sistemine girdi olarak verilerek, yüz veritabanındaki mevcut yüz görüntüleriyle karşılaştırılır. İlgili kişinin yüzü veritabanında bulunan yüzlerden birisiyle eşleştiyse, Şekil 6'da sunulduğu gibi bu kişinin ismi ve giriş-çıkış bilgisi ekrana gösterilmektedir. Ayrıca kişinin giriş-çıkışına ait kimlik ve zaman bilgileri personel veritabanında kayıt altına alınmaktadır.

$\mathrm{Bu}$ çalışmada geliş̧irilen yüz tanıma işlemi için literatürde önerilen yöntemlerden özyüz, fisheryüz ve yerel ikili örüntü histogramı yöntemlerinin üçü ile de testler yapılmıştır. Yapılan testlerde her üç yönteminde gerçek zamanlı personel takibi için başarılı sonuçlar verdiği gözlenmiştir. Tablo 1'de bu yöntemler kullanılarak farklı zamanlarda giriş veya çıkış yapan kişilerin gerçek zamanlı yüz tanıma süreleri karşılaştırılmaktadır. 
Tablo 1: Yüz tanıma sisteminde kullanılan algoritmaların zaman karşılaştırması

\begin{tabular}{l|c|c|c}
\hline & $\begin{array}{c}\text { Yerel İkili Görüntü } \\
\text { Histogramı Algoritması }\end{array}$ & Özyüz Algoritması & Fisheryüz Algoritması \\
\hline Personel 1 & $2,12 \mathrm{sn}$ & $3,28 \mathrm{sn}$ & $4,02 \mathrm{sn}$ \\
\hline Personel 2 & $2,50 \mathrm{sn}$ & $2,20 \mathrm{sn}$ & $2,05 \mathrm{sn}$ \\
\hline Personel 3 & $1,58 \mathrm{sn}$ & $2,84 \mathrm{sn}$ & $1,83 \mathrm{sn}$ \\
\hline Personel 4 & $1,69 \mathrm{sn}$ & $1,85 \mathrm{sn}$ & $2,14 \mathrm{sn}$ \\
\hline Personel 5 & $2,51 \mathrm{sn}$ & $2,50 \mathrm{sn}$ & $1,93 \mathrm{sn}$ \\
\hline Personel 6 & $1,55 \mathrm{sn}$ & $3,29 \mathrm{sn}$ & $3,07 \mathrm{sn}$ \\
\hline Ortalama & $\mathbf{1 , 9 9} \mathbf{~ s n}$ & $\mathbf{2 , 6 6} \mathbf{~ s n}$ & $\mathbf{2 , 5 0 ~ s n}$ \\
\hline
\end{tabular}

Tablo 1'deki deneysel sonuçlar Casper Excalibur G770, i5-10300H 2.50GHz işlemci, 8GB RAM özelliklerine sahip bilgisayar kullanılarak elde edilmiştir. Elde edilen sonuçlara göre, yerel ikili arama histogramı yöntemi ortalama 1,99 saniyede, özyüz algoritması 2,66 saniyede ve fisheryüz algoritması 2,50 saniyede yüz algılama ve tanıma işlemlerini gerçekleştirmektedir. Personelin giriş veya çıkışta kamera karşısındaki pozisyonuna göre yüz tespit sürelerinde farklılıklar olabilmektedir.
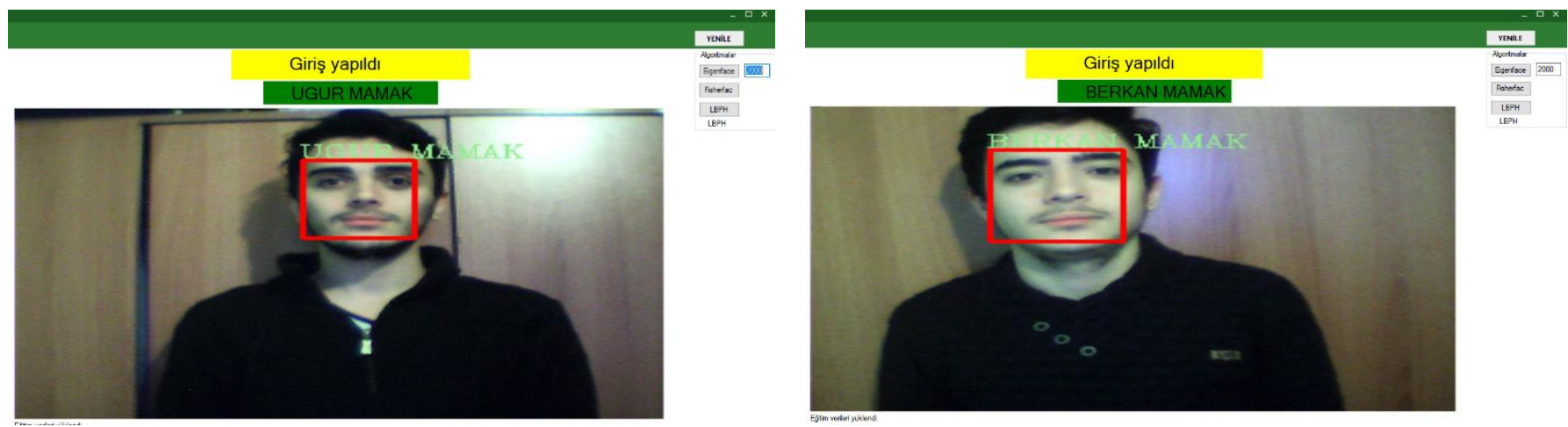

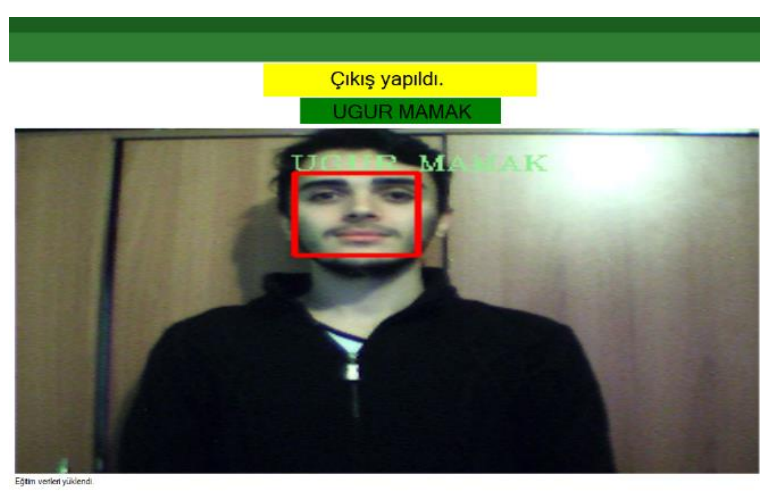

(a)

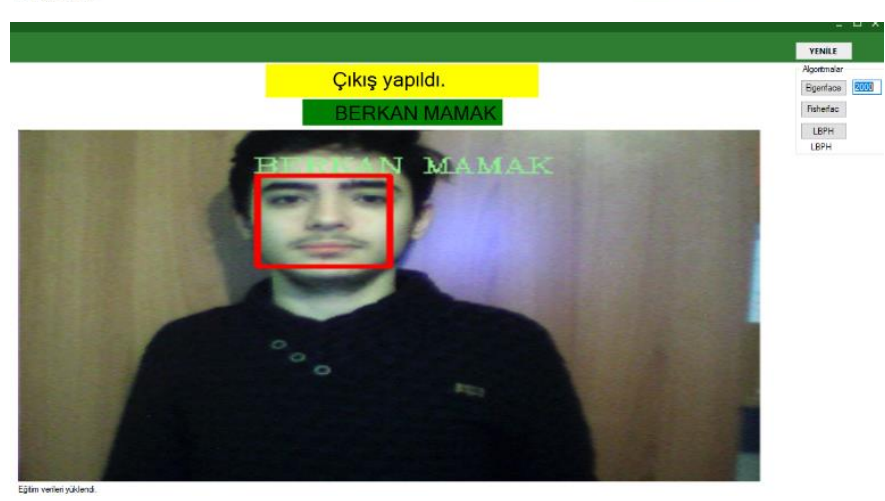

(b)

Şekil 6. Yüz tanıma işlemi sonucu. (a) Birinci personel, (b) ikinci personel

\subsection{Personel Takibi}

Geliştirilen sistemde, çalışan bütün personellerin durumları takip edilebilmektedir. Giriş çıkış işlemlerini veritabanına daha hızlı ve güvenilir şekilde kaydetmek ve güncellemek için personel veritabanında çeşitli prosedürler yazılmıştır. Şekil 7'de giriş çıkış işlemlerinin kayıtlarını sağlayan prosedür kodu gösterilmektedir. Giriş çıkış saatleri arasındaki zaman farkı alınarak personelin aldığı maaşa göre günlük ücreti hesaplanmakta ve kaydedilmektedir. Şekil 8'de çalışan kişilerin farklı günlerde çalışma saatleri ve bu çalışma saatlerine göre alacakları ücret bilgisinin olduğu veritabanı tablosu gösterilmektedir.

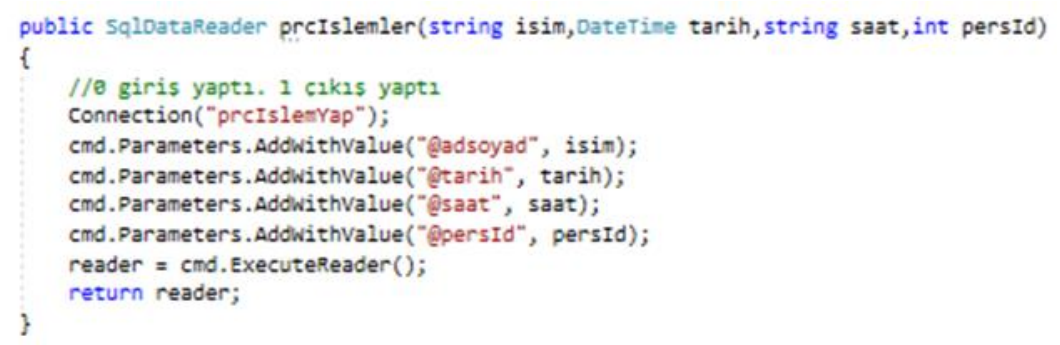

Şekil 7. Giriş çıkışları veritabanına gönderen prosedür fonksiyonu 
European Journal of Science and Technology

\begin{tabular}{|c|c|c|c|c|c|c|}
\hline Islemid & Persld & GirisTarih & GirisSaati & CikisTarih & CikisSaati & GunlukUcret \\
\hline 1] & 2 & $2019-12-2809: 0 \ldots$ & $09: 00: 00$ & $2019-12-2818: 2 \ldots$ & $18: 20: 00$ & 131,2497 \\
\hline 2 & 2 & $2019-12-2909: 2 \ldots$ & $09: 00: 00$ & $2019-12-2918: 2 \ldots$ & $18: 00: 00$ & 131,2497 \\
\hline 3 & 2 & 2019-12-27 09:0... & 09:05:00 & $2019-12-27$ 18:0... & $18: 05: 00$ & 131,2497 \\
\hline 4 & 2 & $2019-12-26$ 10:4 $\ldots$ & $10: 40: 00$ & $2019-12-2620: 3 \ldots$ & $20: 30: 00$ & 145,8330 \\
\hline 5 & 2 & $2019-11-2609: 2 \ldots$ & $09: 00: 00$ & $2019-11-2621: 2 \ldots$ & 21:00:00 & 174,9996 \\
\hline 6 & 3 & 2019-12-29 09:1... & $09: 10: 00$ & $2019-12-2920: 2 \ldots$ & $20: 23: 00$ & 194,7913 \\
\hline 7 & 3 & 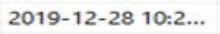 & $10: 23: 00$ & $2019-12-2819: 4 \ldots$ & $18: 40: 00$ & 159,3747 \\
\hline 8 & 3 & $2019-12-2709: 2 \ldots$ & $09: 23: 00$ & $2019-12-2717: 2 \ldots$ & $17: 23: 00$ & 141,6664 \\
\hline 9 & 3 & 2019-11-26 09:0... & $09: 23: 00$ & $2019-11-26 \quad 15: 0 \ldots$ & $15: 45: 00$ & 106,2498 \\
\hline 10 & 3 & $2019-12-3009: 2 \ldots$ & 09:00:00 & $2019-12-3019: 2 \ldots$ & 19:00:00 & 177,0830 \\
\hline 11 & 4 & 2019-11-28 09:0... & $09: 00: 00$ & 2019-11-28 18:0... & $18: 00: 00$ & 168,7500 \\
\hline 12 & 4 & $2019-12-2909: 0 \ldots$ & $09: 00: 00$ & $2019-12-2918: 0 \ldots$ & $18: 00: 00$ & 168,7500 \\
\hline 13 & 7 & 2019-12-29 09:0... & 09:00:00 & 2019-12-29 19:0... & 19:00:00 & 166,6660 \\
\hline 14 & 7 & 2019-12-30 09:0... & $09: 00: 00$ & $2019-12-3106: 0 \ldots$ & $06: 00: 00$ & 349,9986 \\
\hline 15 & 7 & 2020-01-03 11:3... & $11: 13: 47$ & 2020-01-03 19:1... & $19: 15: 48$ & 133,3330 \\
\hline 16 & 7 & 2020-01-17 09:0... & $09: 00: 00$ & $2020-01-1820: 3 \ldots$ & $20: 36: 59$ & 583,3310 \\
\hline 17 & 7 & 2020-01-16 09:0... & $09: 00: 00$ & $2020-01-16 \quad 18: 0 \ldots$ & $18: 00: 00$ & 133,3330 \\
\hline 24 & 5 & 2019-01-14 09:0... & 09:00:00 & 2019-01-14 18:0... & $18: 00: 00$ & 131,2497 \\
\hline 25 & 5 & 2019-01-15 09:0... & $09: 00: 00$ & 2019-01-15 18:0... & $18: 00: 00$ & 131,2497 \\
\hline 26 & 7 & $2020-01-1810: 4 \ldots$ & $20: 42: 16$ & $2020-01-18$ 21:2... & $21: 22: 31$ & 183,3326 \\
\hline
\end{tabular}

Şekil 8. Giriş̧ çıkış işlemlerinin tutulduğu veritabanı tablosu

Bu bilgiler personel veritabanında tutulduğu gibi, geliştirilen arayüz ile yetkili kişilerin ekranında da anlık olarak gösterilmektedir. Şekil 9'de işyerinde bulunan mevcut personeller ve işe geliş saatleri yetkili kişilere gösterilmektedir. Sistemde günlük, aylık veya kişiye göre takip işlemleri listelenebilmektedir. Personellerin gün içerisinde saat kaçta giriş çıkış yaptığı, kaç saat çalıştı̆̆ı, alacağı ücret gibi bilgileri kolayca elde edilmektedir. Doküman oluşturma işlemiyle bütün bilgilerin yazdırılabilir belge formatında arşivlenmesine de olanak sağlanmaktadır.

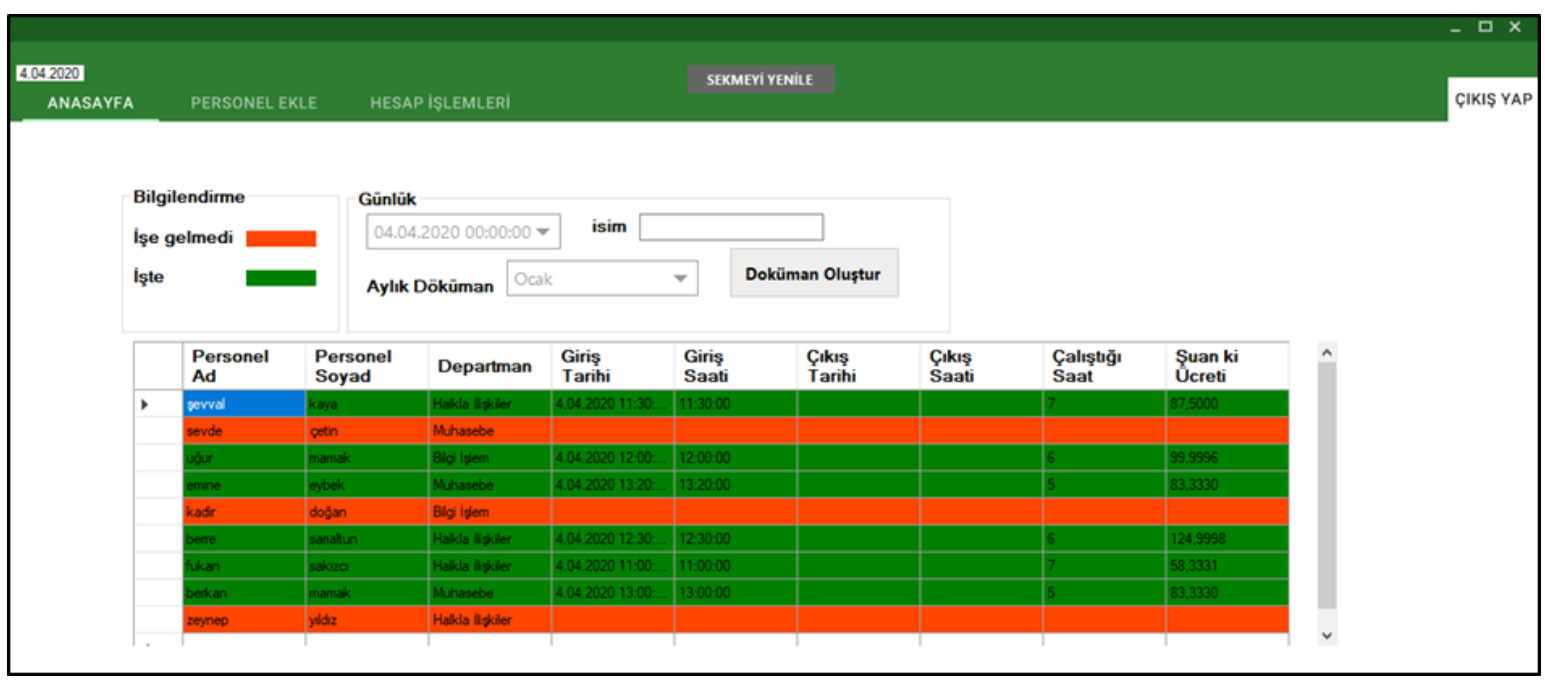

Şekil 9. Anlık personel takip ekranı

Ayrıca yüz tanıma sistemi sayesinde herhangi bir personelin çalı̧̧ma bilgileri kolayca takip edilmektedir. Şekil 10'da örnek bir personel üzerinden mevcut çalışma saati, fazla mesai saati, maaş ve mesai ücreti bilgileri de anlık olarak gösterilmektedir. Bu bilgiler firmalar tarafindan sisteme kaydedilmiş aylık veya haftalık çalışma saati, maaş katsayısı, maaş bilgisi ve mesai saat ücreti gibi bilgilerle otomatik olarak hesaplanmaktadır.

\begin{tabular}{|ll|}
\hline \multicolumn{1}{|c|}{ UGUR MAMAK } & \\
\hline Departman: & Bilgi işlem \\
Ay: & Nisan \\
Maaş: & 4000,0000 \\
Günlük Ücreti: & 160 \\
Mevcut Çalıştı̆ı Gün Sayısı: & $15 / 25$ \\
Çalışmı̧ Olması Gereken Saat(Gün X 8): & 120 \\
Toplam Çalıştı̆ı Saat: & 125 \\
Fazla Mesai Saati: & 5 \\
Fazla Mesai Ücreti: & 250 \\
Şuan ki Toplam Ücret: & 2650 \\
& \\
\hline
\end{tabular}

Şekil 10. Anlık personel çalışma detayları 


\section{Sonuç}

Özellikle çalışan sayısının yüksek olduğu yerlerde, personel giriş çıkışlarının etkili, hızlı ve doğru olarak takip edilmesi zordur. Ayrıca günümüzde yaygın olarak kullanılmakta olan kartlı takip sistemleri güvenlik zafiyetleri bulunmaktadır. Makale kapsamında personel giriş ve çıkışlarının kontrol ve takibi amacıyla yüz tanıma tabanlı bir sistem önerilmiştir. Önerilen yüz tanıma tabanlı takip ve kontrol sistemi biyometrik özellikleri kullandığından bu güvenlik zafiyetlerini önlemektedir. İşlemler otomatik yapıldığı için insan faktöründen kaynaklanan hatalar da en aza indirgenmektedir. Bu sistemle, aynı temas yüzeyine birçok kişinin dokunmasının oluşturacağı sağlıksız koşulların önüne de geçilmektedir. Çünkü personelin giriş ve çıkışlarda kameraya bakması yeterli olup, temas gerektiren herhangi bir işlem yoktur. Dolayısıyla önerilen sistem, maliyeti düşük, etkili, hızlı ve hijyen koşullarına uygun durumdadır. Çeşitli raporlamalar sayesinde, yetkili kişiler personellerinin anlık, günlük veya aylık devam takibini, giriş-çıkış zamanlarını ve fazla mesai bilgilerini sisteme ulaşabildiği her yerden kolayca görebilmektedir.

\section{Kaynakça}

Avuçlu, E., Altun, A. A. \& Elen, A. (2017). Real Time PCA Based Face Recognition for Following Staff, Journal of Selcuk-Technic, 16(1), 1-11.

Bhattacharya, S., Nainala, G. S., Das, P. \& Routray, A. (2018 July). Smart Attendance Monitoring System (SAMS): A Face Recognition based Attendance System for Classroom Environment, IEEE 18th International Conference on Advanced Learning Technologies, Mumbai, 358-360

Erdoğan, A., \& Ilgın, H. (2015). Gürültü içeren insan yüzü görüntülerinde ayrık kosinüs dönüşümü-alt bant tabanlı yüz tanıma. Gazi Üniversitesi Fen Bilimleri Dergisi Part C: Tasarım ve Teknoloji, 3(2), 457-462.

Hatem, H., Beiji, Zou. \& Majeed, R (2015). A Survey of Feature Base Methods for Human Face Detection, International Journal of Control and Automation, 8(5), 61-78.

Holat, R. \& Kulaç, S. (2014 April). ID Identification By Using Face Detection And Recognition Systems, 22nd Signal Processing and Communications Applications Conference (SIU), Trabzon, 866-869.

Huang G. B., Ramesh M., Berg T. \& Miller E. L. (2007). Labeled Faces in the Wild: A Database for Studying Face Recognition in Unconstrained Environments, University of Massachusetts, Amherst, Technical Report 07-49.

Kabasakal, B. (2018). Uzaklık ve cinsiyet tabanlı akıllı reklam görüntüleme sistemi, Yüksek Lisans Tezi, Başkent Üniversitesi Fen Bilimleri Enstitüsü, Ankara.

Kadlag, K., Kale, P. \& Pagar, K. (2016). Intellegent Employee Authentication using RFID and Face Detection International Journal on Emerging Trends in Technology, 3(1), 4083-4085

Kekül, H., Bircan, H., \& Arslan, H. (2018). Yüz tanıma uygulamalarında özyüzler ve yapay sinir ağlarının karşılaştırılması. Uluslararası Yönetim Bilişim Sistemleri ve Bilgisayar Bilimleri Dergisi, 2(1), 51-59.

Kumar, A., Kaur, A. \& Kumar M. (2019) M. Face detection techniques: a review. Artif Intell Rev, 52, 927-948.

Lal, M., Kumar, K., Arain, R. H., Maitlo, A., Ruk, S. A. \& Shaikh, H. (2018). Study of Face Recognition Techniques: A Survey, International Journal of Advanced Computer Science and Applications, 9(6), 42-49.

Nandhini, R., Duraimurugan N. \& Chokkalingam, S. P. (2019). Face Recognition Based Attendance System International Journal of Engineering and Advanced Technology (IJEAT), 8(3), 574-577.

Patel, S., Kumar, P., Garg, S. \& Kumar, R. (2018). Face Recognition based smart attendance system using IOT International Journal of Computer Sciences and Engineering, 6(5), 871-877.

Reddy, K. S. M. (2017). Comparison of Various Face Recognition Algorithms, International Journal of Advanced Research in Science, Engineering and Technology, 4(2), 3357-3361.

Selvi, S. K., Chitrakala, P. \& Jenitha, A. A. (2014). Face Recognition Based Attendance Marking System International Journal of Computer Science and Mobile Computing, 3(2), 337 - 342.

Turan, S. (2017 Nov.). Bilgisayar Laboratuvarlarında Soket İletişim İle Görüntü İşlemeye Dayalı Yoklama Sistemi Tasarımı, International Symposium on Multidisciplinary Studies and Innovative Technologies (ISMSIT), Tokat, 24-28

Vurgun, Y. (2017). Biyometrik yüz tanımaya dayalı web üzerinden güvenli erişim sistemi tasarımı, Yüksek Lisans Tezi, Selçuk Üniversitesi Fen Bilimleri Enstitüsü, Konya. 